\title{
Frequency Model of Credit Payment using Bayesian Geometric Regression and Bayesian Mixture Geometric Regression
}

\author{
Ikacipta Mega Ayuputri*, Nur Iriawan and Pratnya Paramitha Oktaviana \\ Department of Statistics, Faculty of Mathematics, Computing, and Data Science \\ Institut Teknologi Sepuluh Nopember, 60111 Surabaya, Indonesia \\ *Corresponding author: ikaciptamega97@gmail.com
}

Article history

Received: 29 August 2018

Received in revised form: 6 December 2018

Accepted: 17 December 2018

Published on line: 31 December 2018

\begin{abstract}
In distributing funds to customers as credit, multi-finance companies have two necessary risks, i.e. prepayment risk, and default risk. The default risk can be minimized by determining the factors that affect the survival of customers to make credit payment, in terms of frequency of credit payments by customers that are distributed geometry. The proposed modelling is using Bayesian Geometric Regression and Bayesian Mixture Geometric Regression. The best model of this research is modelling using Bayesian Geometric Regression method because it has lower DIC values than Bayesian Mixture Geometric Regression. Modelling using Bayesian Geometric Regression show the significant variables are marital status, down payment, installment length, length of stay, and insurance.
\end{abstract}

Keywords Bayesian; credit payment; geometric regression; mixture model; multi-finance company.

Mathematics Subject Classification 62F15, 62J12, $65 \mathrm{C} 05$.

\section{Introduction}

The failure of customers to make credit payment in multi-finance companies is called default risk. Failure of credit payment is a successful event in a geometry distribution. Therefore, geometric regression can be used to model and to seek some factors which minimize the default risk. Geometric regression is a special case of binomial negative regression with dispersion parameter equal to one. This type of regression cannot be done using ordinary linear modelling, but must be done using the Generalized Linear Model (GLMs). In GLMs, the response variable is assumed to be a member of an exponential family distribution [1].

Works by Rachman [2] showed that the factors that cause failure in returning credit are internal factors and external factors. Internal factors consist of internal debtors and internal banks. External factors are macroeconomic activities or government policies that cannot be predicted by banks, disasters and other unexpected events, and competition between bank institutions. As referred by Hakim [3] down payment has the highest level of significance compared to other variables. In addition, other variables that influence credit survival are 
regions and interest rates. Other studies related to geometric regression modeling have been carried out by Iriawan et al. [4] with a case study of a frequency model of cervical cancer patients in Dr. Soetomo. The study stated that there were no significant parameter estimates using Bayesian geometry regression, but if approached with a negative binomial distribution, there were two significant parameters: number of chemotherapy and anemia status.

The pattern of frequency credit payment to be default is indicated having a mixture distribution, so this also a case of mixture geometric regression. The estimation of this model parameters cannot use the likelihood method because of the difficulties in the computational mixture model. Bayesian estimation method would be applied to overcome this problem. Bayesian would take into account in estimating the parameter of this model based on new information from observed data (samples) and prior knowledge about the parameters [5]. To simplify the process of estimation, Bayesian could use the prior of parameters of geometric regression which is estimated by Maximum Likelihood. It is called as a pseudo prior. Furthermore, the estimation results of mixture geometric regression and non-mixture geometric regression will be compared to get the best modelling based on the smallest DIC (Deviance Information Criterion).

\section{Geometric Regression}

Geometry distribution is one of the exponential family distributions. Based on Agresti [6], a variable random $\mathbf{Y}$ is an exponential family distribution which formulated as follows

$$
f_{Y}(y: \theta, \phi)=\exp \{(y \theta-b(\theta)) / a(\phi)+c(y, \phi)\}
$$

where $a(),. b($.$) and c($.$) are certain functions. If \phi$ is known, then equation (1) is an exponential family with canonical parameter $\theta$. Link function is used to convert GLMs to a linear model. Link function for geometry distribution can be defined as

$$
\begin{aligned}
f(y, p) & =p(1-p)^{y-1} \\
& =\frac{p}{1-p}(1-p)^{y} \\
& =\frac{p}{1-p} \exp (y \ln (1-p) .)
\end{aligned}
$$

Therefore, GLMs for geometry distribution is converted to a linear model using link function $\ln (1-p)$, so geometric regression model can be defined as in equation (3). Parameter $p$ is unknown, so it is estimated based on multiplication of parameter vector and its predictor variable.

$$
\begin{array}{r}
\ln \left(\mathbf{1}-\mathbf{p}_{i}\right)=\mathbf{x}_{i}^{T} \boldsymbol{\beta} \\
\left(\mathbf{1}-\mathbf{p}_{i}\right)=\mathbf{e}^{\mathbf{x}_{i}^{T} \boldsymbol{\beta}} \\
\mathbf{p}_{i}=1-\mathbf{e}^{\mathbf{x}_{i}^{T} \boldsymbol{\beta}}
\end{array}
$$

where $\mathbf{x}_{i}=\left(x_{1_{i}}, x_{2_{i}}, \ldots, x_{\mathrm{p}_{\mathrm{i}}}\right)$ and $\boldsymbol{\beta}^{T}=\left(\beta_{1}, \beta_{2}, \ldots, \beta_{p}\right)$. 


\section{Mixture Geometric Regression Model}

Suppose response variable in regression analysis has more than one distribution, it can be analyzed using a mixture regression model. Detection of mixture model simply through data plot. Each sub-population is a constituent component of a mixture model and has varying proportions for each component. As stated in [7], a mixture model can be defined as

$$
f_{\text {mix }}(z \mid \partial, P)=\sum_{i=1}^{M} P_{i} g_{i}\left(z \mid \partial_{i}\right),
$$

where $f_{\text {mix }}(z \mid \partial, P)$ is density function of the mixture model, $\partial_{i}$ is parameter vector, $k$ is the number of constituent component of the mixture model, $P$ is parameter vector proportion, and $P_{i}$ is a parameter of mixture component proportion which has property $\sum_{i=1}^{M} P_{i}=1$ and $0 \leq P_{i} \leq 1$. Suppose data has $M$ sub-population which each population are distributed geometry, it can be represented as

$$
f_{\text {mix }}(z \mid \mathbf{P}, \mathbf{p})=P_{i} \operatorname{Geom}\left(z \mid p_{1}\right)+\ldots+P_{M} \operatorname{Geom}\left(z \mid p_{M}\right) \text {. }
$$

\section{Bayesian Approach}

Bayesian statistical approach views $\beta$ parameter as a random variable that has a distribution called prior distribution. The prior distribution is used to find posterior distribution so that Bayesian estimator which is mean or mode of posterior distribution is obtained. Let observation $x$ has $\beta$ parameter, the posterior distribution of $\beta$ parameter by using Bayes theorem can be defined as

$$
P(\beta \mid x)=\frac{l(x \mid \beta) P(\beta)}{P(x)} .
$$

Box and Tiao [8] defined prior distribution as preliminary information about parameters. Prior distribution which is determined based on frequentist elaboration result is called pseudo prior. Posterior marginal can be obtained by a very complicated and long-term integration process. Markov Chain Monte Carlo (MCMC) is an approach which can be used to overcome these problems.

\section{Markov Chain Monte Carlo}

The basic idea of MCMC is to generate Markov Chain using iterative Monte Carlo simulation, so stationary posterior distribution is obtained [9]. As referred by Ntzoufras [10], the arrangement of convergent Markov Chain is completed quickly on the target distribution, posterior distribution $P(\beta \mid x)$. MCMC generates sample data of $\beta$ parameter which have certain distribution using Gibbs sampling. Gibbs sampling will divide the $\beta$ parameter into several parts, $\boldsymbol{\beta}=\left(\beta_{1}, \beta_{2}, \ldots, \beta_{p}\right)$. Based on [11], full conditional distribution for each parameter $p\left(\beta_{1} \mid \mathbf{x}, \beta_{2}, \ldots, \beta_{p}\right), \ldots, p\left(\beta_{p} \mid \mathbf{x}, \beta_{1}, \ldots, \beta_{p-1}\right)$ or simply can be defined as $\beta^{(1)}, \beta^{(2)}, \ldots, \beta^{(p)}$. 


\section{Significant Parameter}

Based on [12], parameter estimation results at significance level $\alpha$ can be called significant if occupy criteria in Table 1.

Table 1: Parameter Significance Criteria

\begin{tabular}{|c|c|c|c|}
\hline \multicolumn{3}{|c|}{ Credible Interval } & \multirow{2}{*}{ Estimation Value } \\
\hline$x$ & Median & $1-\alpha$ & \\
\hline+ & + & + & Positive \\
\hline- & - & - & Negative \\
\hline
\end{tabular}

The confidence interval of $\beta$ parameter can be obtained by calculating interval which is centered on media posterior using formula as follows

$$
P(a \leq \mu \leq b)=1-\alpha .
$$

\section{Deviance Information Criterion (DIC)}

If there is more than one model which is suitable to use, then need to choose the best model. Many criteria can be used to determine the best model, one of them is the Deviance Information Criterion (DIC). DIC considers efficient parameters in the model. The formula for obtaining deviance value can be defined as

$$
D I C=\bar{D}(\partial)+P_{D},
$$

where $\bar{D}(\partial)$ is deviance posterior mean and $P_{D}$ is number of efficient parameters in the model. Model with the smallest DIC is the best model than other alternative models [4].

\section{Methodology}

\subsection{Data}

The data that is employed in this research are customer's data of company $\mathrm{X}$ who registered as default customers since June 2010 until February 2018. Company X is one of the used car finance companies. Based on credit payment records during the period, it is known that the data are composed of 334 default customers or unable to pay credit in a pay phase more than 210 days.

\subsection{Model}

Variables used in this research consisted of the response variable $(Y)$ and the predictor variable $(X)$ as follows

$Y=$ frequency of credit payments before customers are declared as default

$X_{1}=$ age of customers when applying for credit

$X_{2}=$ gender of customers $(1=$ man, $0=$ woman $)$ 
$X_{3}=$ marital status of customers is formed by dummy variables $\mathrm{d}_{31}$ and $\mathrm{d}_{32}$.

$\mathrm{d}_{31}$ : married

$\mathrm{d}_{31}=1$, if marital status is married.

$\mathrm{d}_{31}=0$, otherwise.

$\mathrm{d}_{32}$ : divorce

$\mathrm{d}_{32}=1$, if marital status is divorce.

$\mathrm{d}_{32}=0$, otherwise.

$X_{4}=$ amount of down payment is formed by dummy variables $\mathrm{d}_{41}, \mathrm{~d}_{42}$, and $\mathrm{d}_{43}$.

$\mathrm{d}_{41}: 20.1-30 \%$

$\mathrm{d}_{41}=1$, if amount of down payment between $20.1-30 \%$.

$\mathrm{d}_{41}=0$, otherwise.

$\mathrm{d}_{42}: 30.1-50 \%$

$\mathrm{d}_{42}=1$, if amount of down payment between $30.1-50 \%$.

$\mathrm{d}_{42}=0$, otherwise.

$\mathrm{d}_{43}$ : more than $50 \%$

$\mathrm{d}_{43}=1$, if amount of down payment more than $50 \%$.

$\mathrm{d}_{43}=0$, otherwise.

$X_{5}=$ installment time is formed by dummy variables $\mathrm{d}_{51}$ and $\mathrm{d}_{52}$.

$\mathrm{d}_{51}: 25-36$ months

$\mathrm{d}_{51}=1$, if installment time between $25-36$ months.

$\mathrm{d}_{51}=0$, otherwise.

$\mathrm{d}_{52}: 37-48$ months

$\mathrm{d}_{52}=1$, if installment time between $37-48$ months.

$\mathrm{d}_{52}=0$, otherwise.

$X_{6}=$ last education of customers is formed by dummy variables $\mathrm{d}_{61}, \mathrm{~d}_{62}$, and $\mathrm{d}_{63}$.

$\mathrm{d}_{61}$ : junior high school

$\mathrm{d}_{61}=1$, if last education is junior high school.

$\mathrm{d}_{61}=0$, otherwise.

$\mathrm{d}_{62}$ : senior high school

$\mathrm{d}_{62}=1$, if last education is senior high school.

$\mathrm{d}_{62}=0$, otherwise.

$\mathrm{d}_{63}$ : college

$\mathrm{d}_{63}=1$, if last education is college.

$\mathrm{d}_{63}=0$, otherwise.

$X_{7}=$ house ownership status of customers $(1=$ personally, $0=$ family $)$.

$X_{8}=$ time of customers occupies the house (in years).

$X_{9}=$ time of customers works (in years).

$X_{10}=$ installment amount is formed by dummy variables $\mathrm{d}_{101}, \mathrm{~d}_{102}$, and $\mathrm{d}_{103}$.

$\mathrm{d}_{101}$ : Rp 2,000,001 - Rp 3,000,000

$\mathrm{d}_{101}=1$, if installment amount between Rp 2,000,001 - Rp 3,000,000.

$\mathrm{d}_{101}=0$, otherwise.

$\mathrm{d}_{102}$ : Rp 3,000,001 - Rp 4,000,000

$\mathrm{d}_{102}=1$, if installment amount between Rp 3,000,001 - Rp 4,000,000.

$\mathrm{d}_{102}=0$, otherwise.

$\mathrm{d}_{103}$ : more than $\operatorname{Rp} 4,000,000$ 
$\mathrm{d}_{103}=1$, if installment amount more than Rp 4,000,000.

$\mathrm{d}_{103}=0$, otherwise.

$X_{11}=$ insurance premium is formed by dummy variables $\mathrm{d}_{111}, \mathrm{~d}_{112}$, and $\mathrm{d}_{113}$.

$\mathrm{d}_{111}$ : Rp 2,000,001 - Rp 3,000,000

$\mathrm{d}_{111}=1$, if amount of insurance between $\mathrm{Rp} 2,000,001-\mathrm{Rp} 3,000,000$.

$\mathrm{d}_{111}=0$, otherwise.

$\mathrm{d}_{112}$ : Rp 3,000,001 - Rp 4,000,000

$\mathrm{d}_{112}=1$, if amount of insurance between $\operatorname{Rp} 3,000,001-\operatorname{Rp} 4,000,000$.

$\mathrm{d}_{112}=0$, otherwise.

$\mathrm{d}_{113}$ : more than $\mathrm{Rp} 4,000,000$

$\mathrm{d}_{113}=1$, if amount of insurance more than $\mathrm{Rp} 4,000,000$.

$\mathrm{d}_{113}=0$, otherwise.

$X_{12}=$ job type of customers is formed by dummy variables $\mathrm{d}_{121}, \mathrm{~d}_{122}, \mathrm{~d}_{123}, \mathrm{~d}_{124}, \mathrm{~d}_{125}, \mathrm{~d}_{126}, \mathrm{~d}_{127}$, $\mathrm{d}_{128}$, and $\mathrm{d}_{129}$.

$\mathrm{d}_{121}$ : teacher

$\mathrm{d}_{121}=1$, if job type of customers is teacher.

$\mathrm{d}_{121}=0$, otherwise.

$\mathrm{d}_{122}$ : private employee

$\mathrm{d}_{122}=1$, if job type of customers is private employee.

$\mathrm{d}_{122}=0$, otherwise.

$\mathrm{d}_{123}$ : civil servant

$\mathrm{d}_{123}=1$, if job type of customers is civil servant.

$\mathrm{d}_{123}=0$, otherwise.

$\mathrm{d}_{124}$ : entrepreneur

$\mathrm{d}_{124}=1$, if job type of customers is entrepreneur.

$\mathrm{d}_{124}=0$, otherwise.

$\mathrm{d}_{125}$ : farmer

$\mathrm{d}_{125}=1$, if job type of customers is farmer.

$\mathrm{d}_{125}=0$, otherwise.

$\mathrm{d}_{126}$ : retired

$\mathrm{d}_{126}=1$, if job type of customers is retired.

$\mathrm{d}_{126}=0$, otherwise.

$\mathrm{d}_{127}$ : student

$\mathrm{d}_{127}=1$, if job type of customers is student.

$\mathrm{d}_{127}=0$, otherwise.

$\mathrm{d}_{128}$ : housewife

$\mathrm{d}_{128}=1$, if job type of customers is housewife.

$\mathrm{d}_{128}=0$, otherwise.

$\mathrm{d}_{129}$ : BUMN employee

$\mathrm{d}_{129}=1$, if job type of customers is BUMN employee.

$\mathrm{d}_{129}=0$, otherwise.

Mixture geometric regression is using pay endurance variable as a separator. Pay endurance variable is 0 , if customers have a short period of making credit payment to be declared default. Pay endurance variable is 1 , if customers have mid-term of making credit payment to be declared default. If customers have a long period of making credit payment to be declared default, then 
pay endurance variable is 2 . The mixture geometric regression model which has to be estimated is defined by

$$
f(y \mid \mathbf{P}, \mathbf{x}, \boldsymbol{\beta})=P_{\mathbf{1}}\left[\frac{1}{1-e^{\mathbf{x}_{1}^{T} \beta_{1}}}\right]+P_{2}\left[\frac{1}{1-e^{\mathbf{x}_{2}^{T} \beta_{2}}}\right]+P_{3}\left[\frac{1}{1-e^{\mathbf{x}_{3}^{T} \beta_{3}}}\right]
$$

with $P_{1}, P_{2}$, and $P_{3}$ are mixture proportions which have properties $P_{1}+P_{2}+P_{3}=1 . f(y \mid \mathbf{P}, \mathbf{x}, \boldsymbol{\beta})$ represent the probability of customer who is declared a default.

\section{Results and Discussion}

Detection of mixture distribution shows that there are three geometry distributions in the response variables with different $p$ parameters. Classification data into three categories of pay endurance variables is based on the plot of the histogram. Each category of pay endurance variables has mixture proportion $P_{1}=0.54, P_{2}=0.32$, and $P_{3}=0.14$.

Parameter estimation using Bayesian method requires pseudo prior. Pseudo prior is obtained from geometric regression using Maximum Likelihood Estimation (MLE). The result of geometric regression using MLE shows that there are five significant variables: marital status $\left(\mathrm{X}_{3}\right)$, down payment $\left(\mathrm{X}_{4}\right)$, installment time $\left(\mathrm{X}_{5}\right)$, time of customer occupy the house $\left(\mathrm{X}_{8}\right)$, and insurance premium $\left(\mathrm{X}_{11}\right)$. Therefore, modeling using Bayesian method will use all of the significant variables. For Bayesian modeling, we generated 2,000,000 iterations with sampling every 200 iterations.

\subsection{Bayesian Geometric Regression}

There are 50 iteration samples, so that the used sample was 9,950 iterations. It aims to avoid the influence of the initial value. Referring to Table 2, all parameters are significant to the response variable. It can be known through estimation value for each parameter which does not exceed zero in the confidence interval of $2.5 \%$ to $97.5 \%$.

Assuming other predictor variables are fixed, probability and average credit payment until declared as default customer based on a marital status variable is shown in Table 3. Referring to Table 3, customer who is not married has an average frequency of credit payment less than another marital status. If the customer only pays down payment less than $20 \%$ of purchase price, then the average frequency of credit payment is faster declared as default customer than other down payment categories. A customer with installment time less than 25 months is faster declared as default customer than other categories. It may be affected by the installment with short period make installment amount is greater, so it can be a heavy assessment for the customer. Probability customer declared as default which occupies the house in one year is $1-e^{-1.759-0.0473(1)}$ or 0.836 . The average frequency of credit payment is 1 to 2 payments. When customers occupy the house in 10 years, then probability customer declared as default is 0.89 . Therefore, it is known that customer who lives longer, has a greater probability to be declared as default customers. It might happen if the house owner status is not personal property, thus allowing customer has a greater probability to be declared as default customers. Customers with insurance premium more than $\operatorname{Rp} 4,000,000$ have the greatest probability to be declared as default customers. It may occur when the customer paid the insurance premium comes from the loan, so it can be other assessment besides this credit payment. 
Table 2: Result of Parameter Estimation using Bayesian Geometric Regression

\begin{tabular}{|l|c|c|c|c|}
\hline \multicolumn{1}{|c|}{ Parameter } & Estimation & SE & $\mathbf{2 . 5 \%}$ & $\mathbf{9 7 . 5 \%}$ \\
\hline Constant & -1.7590 & 0.0031 & -1.7530 & -1.7650 \\
\hline Marital Status (1) & 0.0871 & 0.0032 & 0.0808 & 0.0933 \\
\hline Marital Status (2) & 0.0536 & 0.0031 & 0.0474 & 0.0598 \\
\hline Down Payment (1) & 0.4472 & 0.0032 & 0.4409 & 0.4533 \\
\hline Down Payment (2) & 0.5506 & 0.0032 & 0.5443 & 0.5568 \\
\hline Down Payment (3) & 0.4846 & 0.0032 & 0.4784 & 0.4910 \\
\hline Installment Time (1) & 0.2605 & 0.0031 & 0.2544 & 0.2666 \\
\hline Installment Time (2) & 0.4940 & 0.0032 & 0.4877 & 0.5002 \\
\hline Time of Customers Occupy The House & -0.0473 & 0.0001 & -0.0475 & -0.0470 \\
\hline Insurance Premi (1) & -0.1235 & 0.0031 & -0.1296 & -0.1172 \\
\hline Insurance Premi (2) & -0.0150 & 0.0031 & -0.0212 & -0.0089 \\
\hline Insurance Premi (3) & -0.1865 & 0.0032 & -0.1926 & -0.1802 \\
\hline
\end{tabular}

\subsection{Bayesian Mixture Geometric Regression}

Similar to non-mixed credit payment modeling, Bayesian mixture geometric regression modeling was obtained based on geometrical regression modeling with Maximum Likelihood Estimation (MLE) for each category. The iteration properties of the parameters with MCMC have been ergodic because they show properties that irreducible, aperiodic and repetitive. Each parameter is normally distributed and converges to one point. The result of estimation parameters with Bayesian mixture geometric regression presented in Table 4. Based on Table 4, it shows that all parameters have a significant effect on each category of credit payments with default customers. The presumed model 1 represents customers who have short payback resistance, the presumed model 2 represents customers with anxiety and the presumed model 3 represents customers with long payback resistance. The proportion of customers with short pay, medium and long is 0.54, 0.32 and 0.14. Therefore, the Bayesian mixture geometric regression model that obtained as follows

$$
\hat{\mu}=\frac{1}{\hat{p}}=0.54\left[\frac{1}{1-e^{\boldsymbol{x}_{1}^{T} \boldsymbol{\beta}_{1}}}\right]+0.32\left[\frac{1}{1-e^{\boldsymbol{x}_{2}^{T} \boldsymbol{\beta}_{2}}}\right]+0.14\left[\frac{1}{1-e^{\boldsymbol{x}_{3}^{T} \boldsymbol{\beta}_{3}}}\right] .
$$

\subsection{Best Model Selection}

The best model was chosen by DIC (Deviance Information Criteria) value. The result of the DIC value that calculated using geometric regression with Bayesian estimation was shown in Table 5 .

The value of the DIC between the two models is not much different. Bayesian geometric regression model has a smaller DIC value compared to the Bayesian mixture geometric regression model, which is a difference of 653 . Therefore, it can be said that the Bayesian geometric regression model is better in modeling the frequency of credit payments. Variables that have a significant effect between the two models are also the same such as the marital status of 
Table 3: Average Frequency of Credit Payment Based on Marital Status

\begin{tabular}{|c|l|c|c|c|}
\hline \multicolumn{2}{|c|}{ Variable } & $\hat{\mathbf{p}}$ & $\hat{\mu}$ & Ratio \\
\hline \multirow{4}{*}{ Marital Status } & Not Married & 0.8278 & 12.080 & - \\
\cline { 2 - 5 } & Married & 0.8121 & 12.314 & 1.02 \\
\cline { 2 - 5 } & Divorce & 0.8183 & 12.221 & 1.01 \\
\hline \multirow{5}{*}{ Down Payment } & $\leq 20 \%$ & 0.8278 & 12.080 & - \\
\cline { 2 - 5 } & $20.1-30 \%$ & 0.7307 & 13.686 & 1.13 \\
\cline { 2 - 5 } & $30.1-50 \%$ & 0.7013 & 14.259 & 1.18 \\
\cline { 2 - 5 } & $>50 \%$ & 0.7204 & 13.881 & 1.15 \\
\hline \multirow{4}{*}{ Timstallment Time of Customers } & $0-24$ months & 0.8278 & 12.080 & - \\
\cline { 2 - 5 } & $25-36$ months & 0.7765 & 12.878 & 1.07 \\
\cline { 2 - 5 } & $37-48$ months & 0.7178 & 13.932 & 1.15 \\
\hline \multirow{5}{*}{ Onsurance Premium } & $\leq c u p y$ The House & 0.836 & 1.196 & - \\
\cline { 2 - 5 } & $2.000 .001-3.000 .000$ & 0.8478 & 11.795 & 0.98 \\
\cline { 2 - 5 } & $3.000 .001-4.000 .000$ & 0.8303 & 12.043 & 1 \\
\cline { 2 - 5 } & $>4.000 .000$ & 0.8571 & 11.667 & 0.97 \\
\hline
\end{tabular}

the customer at the time of applying for a loan, the large down payment (DP) paid, tenor or length of installments, the length of time the customer occupies the house and the amount of insurance premium paid at the beginning.

\section{Conclusion}

The result of geometric regression with Maximum Likelihood Estimation (MLE) shown that five variables are significant. Those variables have a significant effect on the frequency of credit payments before the customer is declared default at $\alpha=10 \%$. Those variables are the marital status of customer status when applying for credit, the amount of down payment (DP) paid, installment time, length of time the customer attends the house and the amount of insurance premium paid in advance. In addition, those variables also have a significant effect on the significance level of $5 \%$ when modeled with Bayesian, both on non-mixture and mixture data. The Bayesian geometric regression model is better for modeling the frequency of credit payments because it has smaller DIC value, which is a difference of 653 . 
Table 4: Result of Parameter Estimation using Bayesian Mixture Geometric Regression

\begin{tabular}{|c|c|c|c|c|c|}
\hline Category & Parameter & Estimation & SE & $2.5 \%$ & $97.5 \%$ \\
\hline \multirow{12}{*}{1} & Constant & -2.022 & 0.003 & -2.016 & -2.029 \\
\hline & Marital Status (1) & 0.039 & 0.003 & 0.033 & 0.046 \\
\hline & Marital Status (2) & 0.073 & 0.003 & 0.067 & 0.079 \\
\hline & Down Payment (1) & 0.236 & 0.003 & 0.230 & 0.242 \\
\hline & Down Payment (2) & 0.412 & 0.003 & 0.406 & 0.418 \\
\hline & Down Payment (3) & 0.133 & 0.003 & 0.127 & 0.139 \\
\hline & Installment Time (1) & 0.212 & 0.003 & 0.206 & 0.218 \\
\hline & Installment Time (2) & 0.483 & 0.003 & 0.476 & 0.489 \\
\hline & Time of Customers Occupy The House & -0.045 & 0.000 & -0.045 & -0.044 \\
\hline & Insurance Premi (1) & -0.082 & 0.003 & -0.088 & -0.075 \\
\hline & Insurance Premi (2) & -0.110 & 0.003 & -0.116 & -0.103 \\
\hline & Insurance Premi (3) & -0.327 & 0.003 & -0.333 & -0.320 \\
\hline \multirow{11}{*}{2} & Constant & -1.668 & 0.003 & -1.662 & -1.674 \\
\hline & Marital Status (1) & 0.796 & 0.003 & 0.789 & 0.802 \\
\hline & Marital Status (2) & 0.355 & 0.003 & 0.349 & 0.361 \\
\hline & Down Payment (2) & -0.414 & 0.003 & -0.420 & -0.408 \\
\hline & Down Payment (3) & -0.423 & 0.003 & -0.429 & -0.416 \\
\hline & Installment Time (1) & 0.381 & 0.003 & 0.375 & 0.387 \\
\hline & Installment Time (2) & 0.189 & 0.003 & 0.183 & 0.196 \\
\hline & Time of Customers Occupy The House & -0.049 & 0.000 & -0.049 & -0.048 \\
\hline & Insurance Premi (1) & -0.188 & 0.003 & -0.194 & -0.182 \\
\hline & Insurance Premi (2) & 0.263 & 0.003 & 0.257 & 0.269 \\
\hline & Insurance Premi (3) & 0.267 & 0.003 & 0.261 & 0.273 \\
\hline \multirow{11}{*}{3} & Constant & -2.544 & 0.003 & -2.538 & -2.551 \\
\hline & Marital Status (1) & -0.155 & 0.003 & -0.161 & -0.149 \\
\hline & Marital Status (2) & 0.275 & 0.003 & 0.269 & 0.282 \\
\hline & Down Payment (2) & 0.176 & 0.003 & 0.169 & 0.181 \\
\hline & Down Payment (3) & 0.299 & 0.003 & 0.292 & 0.305 \\
\hline & Installment Time (1) & 0.568 & 0.003 & 0.562 & 0.574 \\
\hline & Installment Time (2) & 0.885 & 0.003 & 0.879 & 0.892 \\
\hline & Time of Customers Occupy The House & -0.087 & 0.000 & -0.087 & -0.087 \\
\hline & Insurance Premi (1) & 0.252 & 0.003 & 0.245 & 0.258 \\
\hline & Insurance Premi (2) & 0.211 & 0.003 & 0.205 & 0.217 \\
\hline & Insurance Premi (3) & 0.482 & 0.003 & 0.475 & 0.488 \\
\hline
\end{tabular}


Table 5: DIC Value of Bayesian Modeling

\begin{tabular}{|l|c|}
\hline \multicolumn{1}{|c|}{ Model } & DIC \\
\hline Bayesian Geometric Regression & $6,680,000,000,000$ \\
\hline Bayesian Mixture Geometric Regression & $6,680,000,000,653$ \\
\hline
\end{tabular}

\section{References}

[1] Smithson, M. and Merkle, E. C. Generalized Linear Models for Categorical and Continuous Limited Dependent Variables. Boca Raton, Florida:Taylor and Francis Group. 2014.

[2] Rachman, D. K. Analisis Manajemen Risiko Kredit Bermasalah pada Produk Kredit Masyrakat Desa di Bank X Bogor. Ph.D. Thesis. Institut Pertanian Bogor, Bogor. 2011.

[3] Hakim, E. S. Analisa Survival Kredit Perusahaan Pembiayaan Sepeda Motor dengan Menggunakan Proportional Hazard Model (Kasus PT. XXX). Ph.D. Thesis. Universitas Indonesia, Jakarta. 2008.

[4] Irawan, A. R., Iriawan, N. and Purnami, S. W. Pemodelan Perulangan Pengobatan Pasien Kanker Serviks di RSUD Dr. Soetomo dengan Bayesian Geometric Regression dan Bayesian Mixture Geometric Regression. Ph.D. Thesis. Institut Teknologi Sepuluh Nopember, Surabaya. 2017.

[5] Wong, S. Y., Chin, K. S., Tang, D. W., Yang, J. B. and Wang, H. Assessing New Product Development Project Risk by Bayesian Network with a Systematic Probability Generation Methodology. Ph.D. Thesis. Department of Manufacturing Engineering Management City, University of Hong Kong, Hong Kong. 2009.

[6] Agresti, A. Categorical Data Analysis. 3rd Edition. John Wiley and Sons:New Jersey. 2013.

[7] Iriawan, N. Penaksiran Model Mixture Normal Univariabel: Suatu Pendekatan Metode Bayesian dengan MCMC. In Prosiding Seminar Nasional dan Konferda VII Matematika Wilayah DIY \& Jawa Tengah. 2001. 105-110.

[8] Box , G. E. and Tiao,G. C. Bayesian Inference in Statistical Analysis. University of Michigan: Addison-Wesley Pub. Co. 1973.

[9] Sorensen, D. and Gianola, D. Likelihood, Bayesian, and MCMC methods in quantitative genetics. Madison:Springer Science \& Business Media. 2007.

[10] Ntzoufras, I. Bayesian Modeling using WinBUGS. USA:John Wiley and Sons. 2009.

[11] Congdon, P. Bayesian Statistical Modelling. Chichester,UK: John Wiley. 2003.

[12] Gilks, W., Richardson, S. and Spiegelhalter, D. Markov Chain Monte Carlo Practice. London: Chapman and Hall. 1996. 